\section{Beginnings: Establishing a New Journal for Digestive Disease Management}

\author{
Baljendra Kapoor, MD ${ }^{1}$ David C. Madoff, MD² \\ Co-Editors, Digestive Disease Interventions \\ ${ }^{1}$ Department of Radiology, Division of Interventional Radiology, \\ Imaging Institute, Cleveland Clinic, Cleveland, Ohio \\ 2 Department of Radiology, Division of Interventional Radiology, Weill \\ Cornell Medicine, New York, New York
}

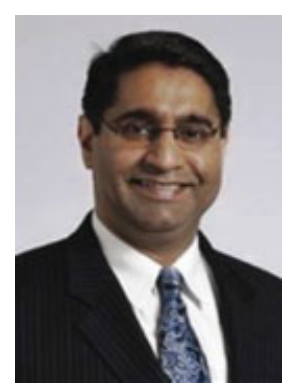

Baljendra Kapoor, MD

Dig Dis Interv 2017;1:1.

Over the last two decades, the field of interventional radiology has developed from a procedure-based specialty to a strong patient care-based clinical specialty working in concert with other medical, oncologic, and surgical specialties. To that end, a multidisciplinary approach to various gastrointestinal disorders has become more common leading to formation of multidisciplinary management care teams and tumor boards with the ultimate goal of providing better patient care. Although this approach has been quite successful, the medical community at large continues to lack the academic integration such that the world of academia remains compartmentalized. Ultimately, the idea of academic inclusivity has been equally lacking in the field of digestive diseases where interventions are provided by various disciplines. From this, the first multidisciplinary meeting of the American Society of Digestive Disease Interventions (ASDDI) was held in Cleveland, Ohio, in September 2014, and was a tremendous success. Based in the increasing number of scientific papers submitted to the second annual meeting of the ASDDI held in Boston, Massachusetts, in October 2015, we believed there was sufficient interest and enthusiasm to start a forum whereby practitioners can enhance the spread of knowledge in this area. Given the lack of journals focused solely on the clinical management, technical innovations and novel therapies related to digestive diseases and their interventions, the idea of starting the journal Digestive Disease Interventions was born.

Digestive Disease Interventions aims to publish high-quality invited review articles, scientific manuscripts, and case reports in the related sciences. Hopefully, the readers from various disciplines will find the published articles useful in their clinical and academic practice. At this time, the journal will be published quarterly with reviews related to specific topics. For the first year, topics to be covered include biliary disease, hepatocellular carci-

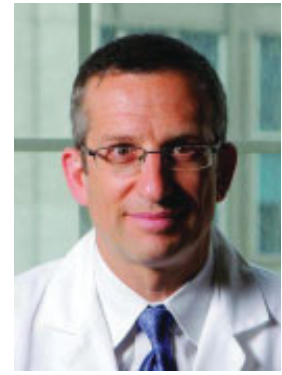

David C. Madoff, MD noma, liver metastases, and portal hypertension, and each issue will be edited by guest editors who are renowned in their respective areas. Over time, we plan to increase the number of scientific submissions, hoping that the journal will become a bimonthly or monthly endeavor.

We would like to extend warm and sincere thanks to the publisher, Thieme, for their commitment to Digestive Disease Interventions and having the vision and understanding that this field has been lacking a high-quality and focused journal. We also want to thank our international editorial board whose work in this area has aided in the advancement of patient care and interventions related to digestive diseases. Last, we hope that the readers of Digestive Disease Interventions will find the articles to be of great interest and quality, and plan to submit their highest-quality work to it.

We look forward to a successful first year of Digestive Disease Interventions.
Address for correspondence Baljendra Kapoor, MD, Department of Radiology, Division of Interventional Radiology, Imaging Institute, Cleveland Clinic, 9500 Euclid Avenue, L10 Cleveland, OH 44195 (e-mail: kapoorb@ccf.org).
Issue Theme Biliary Diseases and Interventions; Guest Editor, Ronald S. Arellano, MD
Copyright $\odot 2017$ by Thieme Medical Publishers, Inc., 333 Seventh Avenue, New York, NY 10001, USA. Tel: +1(212) 584-4662.
DOI https://doi.org/ 10.1055/s-0037-1600137. ISSN 2472-8721. 